\title{
Los trabajadores gráficos entre 1916 y 1943 : estructura sindical, influencia de la izquierda y organización en el lugar de trabajo
}

\section{Graphical workers between 1916 and 1943: union structure, influence of the left and workplace organization}

\author{
Diego Ceruso \\ Consejo Nacional de Investigaciones Científicas y Técnicas \\ Universidad de Buenos Aires \\ (Argentina) \\ diegoceruso@gmail.com
}

Nuestro objetivo es analizar un gremio escasamente abordado por los estudios que posicionaron su mirada en el mundo del trabajo en la Argentina durante las décadas de 1920 a 1940. Nos referimos al importante sector de la industria gráfica de Buenos Aires y alrededores. El trabajo tiene tres ejes: en primer lugar, nos enfocamos en la organización gremial, para describir la presencia de los sindicatos únicos por rama industrial, sus características internas y la dinámica de los conflictos en los que se vieron envueltos trabajadores, empresarios y Estado; en segundo lugar; observaremos el papel de la intervención de las diferentes tendencias ideológicas del movimiento obrero (anarquistas, socialistas, sindicalistas y comunistas), procurando mensurar la influencia de cada una de ellas en el gremio y conceptualizando sus estrategias políticas y organizativas; por último, posaremos nuestra mirada sobre la organización en el lugar de trabajo. En función de estos propósitos, examinamos una vasta red de fuentes primarias, que abarcan materiales de origen empresarial y estatal, así como los periódicos de los distintos sindicatos del sector y de las corrientes que allí actuaron.

Palabras Clave: Gráficos - Estructura sindical- Izquierda- Organización en el lugar de trabajo - Período de entreguerras. 


\begin{abstract}
The aim of this article is to analyze a guild scarcely covered by studies that were focused on the world of work in Argentina during the 1920s to 1940s. We refer to the important sector of the printing industry of Buenos Aires and surrounding area. This work takes into account three fundamental axes. First, we analyze trade organization in order to describe unique industrial unions, their internal characteristics and the conflicts in which workers, employers and the state were involved. In second place, the role of different ideological tendencies of labor movement (anarchists, socialists, sindicalistas and communists). We explore then with the intention of measuring the influence of each one in the guild and conceptualizing their political and organizational strategies. Finally, we consider workplace organization. We are interested in examine a wide network of primary sources: business and State archives and newspapers of different unions and ideological tendencies.
\end{abstract}

Key Words: Graphic workers - Union structure - Left - workplace organization - Interwar period.

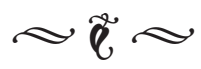

\section{Introducción}

El gremio gráfico se encuentra entre los sectores de mayor tradición del movimiento obrero argentino. Con estructuras asociativas que datan de mediados del siglo XIX, como la Sociedad Tipográfica Bonaerense a partir de 1857, supo constituirse en una referencia ineludible en el mundo del trabajo. ${ }^{1}$ Iniciado el siglo $\mathrm{XX}, \mathrm{y}$ en un período de marcada conflictividad, el sector contaba con cuatro entidades: la Unión Gráfica, de influencia socialista, la Federación de Artes Gráficas, anarquista, $y$ dos que agrupaban por principio de nacionalidad, una francesa y la otra alemana. ${ }^{2}$

1. En términos estrictos, la Sociedad Tipográfica Bonaerense no se trataba de un sindicato pues era una estructura de marcado tinte corporativo en defensa de un oficio e incluyó entre sus integrantes tanto a obreros como a pequeños y medianos productores.

2. DI TELLA, Torcuato, Perón y los sindicatos. El inicio 44
Tras una huelga en 1906, estas sociedades se unificaron y formaron la Federación Gráfica Bonaerense (FGB), nacida el 3 de mayo de 1907. Inicialmente, la corriente sindicalista ejerció su influencia en el sindicato aunque con gran presencia de los socialistas que, ya en la década de 1920, plasmarían su preponderancia en la conducción.

Para 1914, en la Capital Federal, se registraban 511 establecimientos gráficos en los que trabajaban 7.675 obreros que ascendían a 1.439 y 13.286 , respectivamente, si tomamos el total del país. ${ }^{3}$ Según el mismo censo, había 48.779 establecimientos industriales en todo

de una relación conflictiva, Ariel, Buenos Aires 2003, pp. 158 y ss.

3. Tercer Censo de Población. Levantado el $1^{\circ}$ de junio de 1914, T. VII, Censo de las Industrias, Buenos Aires, 1917, pp. 320 y 403, respectivamente. 
el país en los que trabajaban 410.201 obreros. $^{4}$ Durante la segunda mitad de la década de 1910, pero más marcadamente en los años veinte, el sector asistió a un fuerte proceso de centralización del capital, aumento de la magnitud de las unidades productivas y el pasaje a la etapa de gran industria en términos del proceso de trabajo. ${ }^{5}$ Esta concentración se vio impulsada tras la crisis ocurrida en torno a la Primera Guerra Mundial cuando un conjunto de empresas adquirieron, por compra o fusión, a otras de menor dimensión que no pudieron costear el proceso de innovación tecnológica ni sobrellevar las consecuencias del estancamiento económico general. ${ }^{6}$ Como veremos, el escenario se complementaba con la apertura de un ciclo de conflictividad de gran magnitud. El artículo que aquí presentamos tiene como objetivo el análisis del gremio gráfico en una doble faz: primero, el examen de la estructura y las formas de organización sindical junto a la indagación de la representación política de los obreros en los lugares de trabajo; por otro lado, investigar y ponderar la influencia e inserción que tuvo cada corriente político-ideológica de la izquierda en el gremio. Estos dos elementos

4. DORFMAN, Adolfo, Historia de la industria argentina, Hyspamérica, Buenos Aires, 1986, p. 296.

5. BIL, Damián, Descalificados: proceso de trabajo y clase obrera en la rama gráfica (1890-1940), Ediciones RyR, Buenos Aires, 2007, pp. 38-44.

6. Existen valiosos trabajos que abordaron este importante gremio con posterioridad a 1943. En GHIGLIANI, Pablo, "La Federación Gráfica Bonaerense y la irrupción del peronismo", en Sociobistórica Cuadernos del CISH, La Plata, 1998, V. III, No 4, pp. 77-115, se hace un importante aporte al análisis del gremio gráfico, el desempeño de las comisiones internas y al impacto provocado por la aparición del peronismo y el nuevo modelo sindical a partir de allí. También relevante es el texto, de corte periodístico: FERRER, Nelson, Historia de los gráficos argentinos. Sus luchas, sus instituciones (18571957), Dos Orillas, Buenos Aires, 2008. se abordan con la intención de encarar el vínculo permanente entre ambos pues así, entendemos, se enriquece el estudio.

\section{Del inicio del ciclo de huelgas al quiebre del año 1930}

La historiografía ha señalado la fase ascendente del movimiento obrero a partir de 1916 destacando la apertura de un ciclo huelguístico de gran envergadura. ${ }^{7}$ La novedad estuvo dada por la presencia del aumento de conflictos encabezados por obreros industriales. Numerosos autores sostienen que en torno a la finalización de la Primera Guerra el sector industrial comenzó a mostrar señales de crecimiento diferenciados con respecto al resto de la economía y, en particular, al sector agropecuario. El paulatino agotamiento de la frontera agrícola-ganadera, la suba de precios de algunos productos manufacturados, el reposicionamiento de la inversión extranjera hacia el sector industrial, entre otros factores, posibilitaron una dinámica de crecimiento, tenue pero sostenida, en estas áreas. ${ }^{8}$ Esto no significó el inicio de la producción industrial en la Argentina pues existían sectores, como los frigoríficos, que tenían una extendida presencia en este sentido.

Entre finales de 1916 y comienzos de 1917, los años más acuciantes por el aumento récord del número de desocupados y el deterioro

7. Por ejemplo: DEL CAMPO, Hugo, Sindicalismo y peronismo. Los comienzos de un vinculo perdurable, Siglo Veintiuno Editores, Buenos Aires, 2005, p. 46; ROCK, David, El radicalismo argentino, 1890-1930 (1977), Amorrortu, Buenos Aires, 2010, pp. 141 y ss.

8. Entre otros: KOROL, Juan Carlos y BELINI, Claudio, Historia económica de la Argentina en el siglo XX, Siglo Veintiuno Editores, Buenos Aires, 2012. 
del salario real, se dispuso un escenario en donde la protesta se incrementó entre quienes conformaban la viga estructural del movimiento obrero como los obreros ferroviarios y marítimos. Aunque estos sectores ligados al transporte fueron quienes marcaron el pulso, en el inicio de este nuevo ciclo de conflictividad sobrevino una novedad cualitativa con respecto a los precedentes: el dinamismo en el proceso de organización y confrontación de los gremios industriales. En este sector se sucedieron una serie de huelgas de gran repercusión: entre 1917 y 1918 los obreros frigoríficos produjeron violentos conflictos en Zárate, Berisso y Avellaneda; la huelga metalúrgica de 1919 iniciada en los talleres Vasena; los trabajadores de la industria del calzado también impulsaron reivindicaciones en 1918 y ese mismo año se sucedieron diferentes paros de magnitud en la provincia de Córdoba en los gremios del calzado, gráficos, madera y construcción, entre otras.

En este marco, en 1919, los obreros gráficos encabezaron un reclamo por la instalación de las 44 horas semanales de trabajo, entre varias demandas. Los primeros movimientos comenzaron en el mes de febrero con conflictos con los linotipistas de la empresa Lorenzo J. Rosso y los trabajadores de los periódicos La Nación y La Razón, entre otros. Las negociaciones fueron protagonizadas por la FGB y por la Sección Artes Gráficas de la Unión Industrial Argentina (UIA) que propiciaba la anulación del convenio. ${ }^{9} \mathrm{La}$ FGB impulsó durante los meses siguientes la actividad gremial con la búsqueda de sindicalización y la realización de huelgas

9. Boletín de la Unión Industrial Argentina, 603, Buenos Aires, 15/3/19, p. 30. parciales, de corta duración y en talleres específicos. Finalmente, en mayo elevaron un pedido de aumento salarial y de reducción de la jornada que empalmó con el boicot a la firma Gath \& Chaves que emprendieron las trabajadores de la confección y al cual se plegaron los gráficos. Los empresarios respondieron con la declaración del lockout en pos de la "libertad de prensa". A pesar de la solidaridad de algunos sectores y de la organización del sindicato, la dura oposición sólo permitió a los obreros conquistas parciales y el movimiento se debilitó a mediados de junio $y$ fue parcializado paulatinamente hasta el mes de diciembre cuando finalizó. La FGB quedó debilitada en las principales firmas y el convenio colectivo para la rama en su conjunto fue suspendido y reemplazado por las negociaciones por empresa. ${ }^{10}$

En la derrota de los trabajadores influyó la reacción de la Asociación del Trabajo y la Liga Patriótica Argentina que impulsaron la creación de la Asociación Gráfica como entidad patronal para alimentar el lockout, nutrir de rompehuelgas a las empresas y atacar a los trabajadores. ${ }^{11}$ Esto colocó en retroceso al gremio durante los siguientes años pero el sindicato, como veremos, no cesó en su búsqueda por obtener presencia efectiva en los diferentes talleres. ${ }^{12}$

10. BADOZA, María Silvia y TATO, María Inés, "Cuando Buenos Aires se quedó sin diarios: los conflictos de 1919 en la prensa gráfica argentina”, en Sociobistórica Cuadernos del CISH, La Plata, 2006, No 19-20, pp. 113138. Disponible en: <http://www.sociohistorica.fahce. unlp.edu.ar/article/view/SHn19-20a05>

11. RAPALO, María Ester, Patrones y obreros. La ofensiva de la clase propietaria, 1918-1930, Siglo Veintiuno Editores, Buenos Aires, 2012, pp. 112-117.

12. La Protesta, Buenos Aires, 8/12/1922, p. 4. 
Durante gran parte de la década de 1920 el sector de los gráficos acompañó el reflujo general. La clase obrera comenzaba a transitar el sendero posterior a un ciclo que había finalizado en derrota y del cual le costó recuperarse. Tras la salida del ciclo de protestas, las corrientes políticas con presencia en el movimiento obrero se dispusieron a la discusión alrededor de la unidad de los trabajadores en una sola central sindical. Para ello, se llamó a un encuentro que finalmente se reunió en el teatro Verdi del barrio de La Boca en marzo de 1922.

El Congreso de Unidad contó con la presencia de 102 organizaciones de la FORA IX Congreso, 60 entidades autónomas y 14 de la FORA V Congreso. Tras el debate, el surgimiento de la Unión Sindical Argentina (USA) materializó una central obrera que plasmaba pocos cambios respecto de la FORA IX Congreso. El escaso número de sindicatos le alcanzaba para erigirse como la entidad de mayor tamaño, con 27.000 cotizantes, pues la FORA V Congreso (de aquí en más la denominaremos sólo FORA) tenía apenas un puñado de organizaciones en su interior. De inmediato, la USA confirmó la preeminencia sindicalista en sus estatutos y lo plasmó en su conducción designando a Alejandro Silvetti, del gremio de la madera, como secretario general. ${ }^{13}$ Las ideas programáticas de la USA ligadas a la autonomía de los partidos, la prescindencia de la política y la visión ensimismada sobre el proceder sindical fueron argumentos suficientes para las disputas con el socialismo y el comunismo. ${ }^{14}$ Pero el motivo principal de

13. MAROTTA, Sebastián, El movimiento sindical argentino. Su génesis y desarrollo. Período 1920-1935, T. III. Lacio, Buenos Aires, 1970, pp. 51-90.

14. ODDONE, Jacinto, Gremialismo proletario argentino, su renguera fue la ausencia de La Fraternidad y la Federación Obrera Ferrocarrilera (que en el transcurso de 1922 cambió su nombre por el de Unión Ferroviaria) que habían conformado el viejo anhelo de unidad en la Confraternidad Ferroviaria y se mantuvieron al margen de la central naciente. Ello le quitó a la USA un componente fundamental e hizo que exhibiera en los años siguientes una merma numérica significativa respecto a la FORA IX Congreso. Los gráficos, que tenían una importante presencia en la FORA IX Congreso, se habían adherido de modo fugaz a la Internacional Sindical Roja por presión del grupo comunista. ${ }^{15}$ Tras este breve episodio, la FGB se desenvolvió al interior de la USA durante los años veinte.

Los socialistas, por su parte, criticaron los principios sobre los cuales se erigió la USA pero inicialmente funcionaron dentro de ella. Por ejemplo, tanto la Unión de Obreros y Empleados Municipales como la Unión Obreros Curtidores se sumaron a la central aunque fugazmente. $\mathrm{El}$ supuesto apoliticismo sindicalista fue denunciado como sectario en reiteradas ocasiones por los socialistas que tenían algunas posiciones ganadas a través de los años en el movimiento sindical. Además, su presencia entre los ferroviarios y gráficos, como también en el sector de la confección, dotaban a esta corriente de una cierta

La Vanguardia, Buenos Aires, 1949, pp. 305-306; ISCARO, Rubens, Historia del movimiento sindical, T. IV, Fundamentos, Buenos Aires, 1973, pp. 13-15.

15. Entre los miembros del Consejo Federal de la FORA estaban: Sebastián Marotta (linotipista), Luis Lauzet (linotipista), Serna Pacheco (tipógrafo), José Penelón (tipógrafo), Manuel González Maseda, (encuadernador) y Juan Pallas (linotipista). MAROTTA, Sebastián, El movimiento sindical argentino. Su génesis y desarrollo. Periodo 1907-1920, T. II, Lacio, Buenos Aires, 1961, pp. 238-239. 
investidura gremial. El reverso del logro era la persistente voluntad que, desde su fundación, el PS mostró, aunque con debate interno, de escindir la política gremial de la partidaria. En la práctica, esto implicó una predilección por la lucha electoral en perjuicio de poseer una estrategia en el movimiento obrero que diera lugar a un desarrollo uniforme. ${ }^{16} \mathrm{La}$ autonomía de las dirigencias sindicales entre sí y respecto del PS dificultó durante este período el grado de coordinación dada la ausencia notoria de un programa gremial para los trabajadores.

El caso del forismo continuaba por el camino antes señalado con la escasa voluntad evidente de discutir sus preceptos. En particular, quedaba explícito que se encontraba desligado de la voluntad de crear estructuras en los lugares de trabajo. Es conocido el rechazo explícito a la organización por rama industrialy, emparentada a ello, a la presencia de instancias en las plantas de trabajo de modo colectivo. Puede registrarse de modo fragmentario la presencia y el impulso al funcionamiento del delegado entre los metalúrgicos y albañiles por parte de los anarquistas como así también en el gremio gráfico, como el caso de una huelga en el taller Bernard. ${ }^{17}$

A la ya mencionada mayoría sindicalista y socialista en la FGB, le sobrevino una novedad a mediados de la década del veinte. Los comunistas, que habían tenido escasa incidencia

16. CAMARERO, Hernán, "Socialismo y movimiento sindical: una articulación débil. La COA y sus relaciones con el PS durante la década de 1920", en CAMARERO, Hernán y HERRERA, Carlos Miguel (editores) El Partido Socialista en Argentina: sociedad, política e ideas a través de un siglo, Prometeo, Buenos Aires, 2005, pp. 185-217.

17. La Protesta, Buenos Aires, 8/12/1922, p. 4. Para los otros casos mencionados ver La Protesta, Buenos Aires, 22/10/1922, p. 4. en el movimiento obrero en la primera mitad de la década de 1920, se lanzaron a revertir esta situación. El V Congreso de la Comintern que se desarrolló a mediados de 1924 selló la definitiva dirección hacia la 'bolchevización' y la 'proletarización'. La primera implicaba un PC cada vez más sometido a la deriva de Moscú y la adopción de un 'centralismo democrático' reinterpretado como una pérdida de autonomía de las instancias inferiores partidarias. Además, significó modificaciones en la estructura interna, la aplicación de las células y un mayor compromiso militante, entre diversas cuestiones. Por su parte, la 'proletarización' buscaba definir un mayor perfil obrero al partido mediante el fomento y adopción de la estructura de células sobre las cuales se debía basar la reorganización: "gran parte de la labor partidaria giró alrededor, de la conformación, mantenimiento y extensión de esas células y comités, a los que nutrió de actividades e instrumentos específicos. El más relevante fue el periódico de empresa, original órgano de prensa que llevó la influencia del comunismo hasta la base misma de la experiencia obrera, la que germinaba en el ámbito de la producción". ${ }^{18}$ Así, buscaron impactar en el sector gráfico pero su influencia en el plano celular les sirvió para obtener una presencia más bien módica que no impactó de modo relevante en las sólidas, y de larga data, posiciones sindicalistas y principalmente socialistas.

En 1927, se constituyó la Federación Obrera Poligráfica Argentina (FOPA) que aglutinó a la gran mayoría de los sindicatos gráficos del país y en la cual la figura de Marotta se

18. CAMARERO, Hernán, A la conquista de la clase obrera. Los comunistas y el mundo del trabajo en la Argentina, 1920-1935, Siglo Veintiuno Editora Iberoamericana, Buenos Aires, 2007, pp. 347-348. 
destacaba. Al año siguiente, en 1928, la FGB logró el restablecimiento del convenio colectivo y la firma de una serie de reivindicaciones: normativa para las horas extras, abolición del destajo, igualación de salario entre hombres y mujeres, entre las principales. Aunque también allí los empresarios lograron plasmar medidas nocivas para los derechos obreros como el período de prueba con despedido sin aviso previo, el mantenimiento de la limpieza de máquinas por parte de los trabajadores y, más importante para nosotros, la prohibición de impulsar propaganda dentro de las fábricas y talleres. Pero las consecuencias del conflicto de 1928 fueron más allá. Los linotipistas consideraron que el restablecimiento del convenio no atendía algunas de sus reivindicaciones específicas y conformaron una nueva agrupación que, tras la decisión de la FGB de suspenderlos como asociados, se convirtió en sindicato: la Unión Linotipista Mecánicos y Afines (ULMA), conducida por Sebastián Marotta. ${ }^{19}$ Allí no faltaron las cuestiones políticas pues desde el sindicalismo se argumentaba que la FGB era "una sucursal del Partido Socialista". ${ }^{20}$ Los cruces entre las corrientes políticas no se limitaron al socialismo y al sindicalismo dado que en el gremio había una presencia comunista en aumento. El Partido Comunista (PC), que contaba con la figura de José Penelón desde sus comienzos, aumentó su incidencia conforme avanzaron los años veinte aunque en 1927, de modo fugaz, vio afectada su influencia tras el alejamiento de Penelón y la posterior ruptura y conformación del Partido Comunista de la

19. MAROTTA, Sebastián, El movimiento sindical argentino. Su génesis y desarrollo. Periodo 1920-1935..., Op. Cit., p. 270.

20. DI TELLA, Torcuato, Perón y los sindicatos..., Op. Cit., p. 155.
Región/República Argentina, que luego de 1930 adoptó el nombre de Concentración Obrera. Penelón contaba con vastos pergaminos que le permitieron aglutinar un respetable grupo de obreros gráficos, aunque muchos retornaron rápidamente a la estructura oficial. ${ }^{21}$ Para completar el panorama, el anarquismo contaba con un número menor de militantes y su incidencia declinante se emparentaba con su accionar en el conjunto del movimiento obrero.

En julio de 1928, la FOPA realizó un llamado oficial a la Confederación Obrera Argentina (COA) y la USA, también a los sindicatos autónomos, con el fin de iniciar el camino a la ansiada concreción de la unidad en una central de trabajadores que aglutinara a todas las expresiones sindicales del movimiento obrero. ${ }^{22}$ La FOPA era un reflejo de la FGB en la diversidad y presencia de las corrientes políticas: Pedro Porcel (socialista) era el secretario general, Sebastián Marotta (sindicalista) era prosecretario y Manuel Punyet Alberti (comunista) era el protesorero. ${ }^{23} \mathrm{En}$ el ofrecimiento se adujo haber invitado a la FORA aunque no queda claro si existieron negociaciones al respecto.

21. Penelón fue concejal en los períodos 1921-1924 y 1927-1930. Con su nuevo partido, lo fue en 19321936 y 1938-1941. Entre otros: CERUSO, Diego, “E1 comunismo argentino y sus divisiones en los años veinte. Un análisis de la disputa en el movimiento sindical entre el 'penelonismo' y el Partido Comunista", en Izquierdas, una mirada histórica desde América Latina, Santiago, 2014, No 18, pp. 37-56. Disponible en: <http://www.izquierdas. cl/ediciones/2014/numero-18-abril-2014>

22. Comunicado oficial de la FOPA en MAROTTA, Sebastián, El movimiento sindical argentino. Su génesis y desarrollo. Período 1920-1935..., Op. Cit., p. 292.

23. GODIO, Julio, El movimiento obrero argentino (19101930). Socialismo, sindicalismo y comunismo, Legasa, Buenos Aires, 1988, p. 409. 
De todos modos, inmediatamente desde La Protesta se rechazaron las gestiones por considerar que se hacía sobre los principios del reformismo. ${ }^{24}$ Por su parte, los comunistas apoyaron las negociaciones para la fusión en un principio pero, a fines de 1928, conformaron el Comité de Unidad Sindical Clasista, como organismo propio. Aunque ciertamente fue una unificación fogoneada por las cúpulas gremiales sin presencia de las bases, como aducían, los comunistas, que vociferaban una unidad etérea, no se sumaron a causa de su sectaria línea estratégica de 'clase contra clase'.

En definitiva, la comisión que encaró las gestiones por la unidad comenzó sus labores ese mismo año y estuvo integrada por Alejandro Silvetti, por la USA, José Negri, por la COA, y Sebastián Marotta, por la FOPA. ${ }^{25}$ Las negociaciones se extendieron durante 1929 hasta que a comienzos de 1930 primero la USA aprobó la unidad, a través del voto en las asambleas sindicales, y luego lo hizo la COA, que prefirió el voto general de los afiliados, concretando hacia el mes de septiembre, y con posterioridad al golpe de Estado, la disolución de las centrales y la formación de la Confederación General del Trabajo (CGT) en la que también ingresaron importantes sindicatos autónomos. ${ }^{26}$ Así, la central rondó en su versión inicial los 125.000 integrantes, lo que la convertía en la más numerosa hasta ese

24. MATSUSHITA, Hiroshi, Movimiento Obrero Argentino 1930-1945: Sus proyecciones en los orígenes del peronismo, Hyspamérica, Buenos Aires, 1986, p. 56.

25. Bandera Proletaria, Buenos Aires, 6/10/1928, p. 1.

26. ODDONE, Jacinto, Gremialismo..., Op. Cit., p. 331; MAROTTA, Sebastián, El movimiento sindical argentino. Su génesis y desarrollo. Período 1920-1935..., Op. Cit., p. 294 y ss. momento. ${ }^{27}$ La dirección quedó conformada de la siguiente manera: Luis Cerutti secretario general (COA, Unión Ferroviaria), Silvetti prosecretario (USA, sindicato del mueble y luego de estatales), Andrés Cabona tesorero (USA, sindicato del mimbre y luego de estatales), José Negri protesorero (COA, Unión Ferroviaria), además de seis vocales (tres para cada una de las representaciones) que completaban la Junta Ejecutiva. El peso de los ferroviarios en la central era indudable aunque esto no implicaba necesariamente supremacía socialista pues el sindicalismo allí había ganado posiciones con la figura, siempre tendiente a la negociación y al pragmatismo, de Antonio Tramonti y por la recurrente laxitud de la relación entre el PS, sus afiliados y sus dirigentes sindicales. ${ }^{28}$

\section{De la crisis de 1930 al golpe de Estado de 1943}

El escenario argentino mostraba un crecimiento de la producción manufacturera para fines de la década de 1920 en paralelo a una mayor inversión en el sector industrial y un incremento de la fuerza de trabajo ocupada por sobre el índice de nuevos establecimientos. ${ }^{29}$ Esta situación marcaba un

27. DEL CAMPO, Hugo, Sindicalismo y peronismo..., Op. Cit., p. 104 y ss.

28. TORTTI, María Cristina, Notas sobre la estrategia del Partido Socialista. Reformismo politico y reformismo sindical, Serie Conflictos y Procesos de la Historia Argentina Contemporánea No 34, CEAL, Buenos Aires, 1989; ARICÓ, José, La hipótesis de Justo. Escritos sobre el socialismo en América Latina, Sudamericana, Buenos Aires, 1999; CAMARERO, Hernán, "Socialismo y movimiento sindical...”, Op. Cit., pp. 185-217.

29. IRIGOIN, Alfredo, "La evolución industrial en 
aumento de las dimensiones de las unidades productivas entre los que sobresalían el rubro textil, el metalúrgico, la industria química y las alimenticias. Pero el paisaje global se modificó en lo inmediato.

La crisis de fines de 1929, en la cual se produjo el crac de la Bolsa de Nueva York, dio inicio a un cambio de paradigma económico mundial. La universalidad y dimensión de los eventos perturbó los cimientos de un capitalismo que pregonaba, más allá de vaivenes coyunturales, la existencia de un crecimiento constante y un progreso inevitable. Las consecuencias inmediatas fueron la caída de los precios internacionales, la ruptura de los lazos comerciales, la elaboración por parte de los países de medidas proteccionistas, el abandono del patrón oro, las devaluaciones de las monedas y la construcción de acuerdos bilaterales entre naciones que reemplazaron la multilateralidad previa. $^{30} \mathrm{La}$ Argentina no quedó indemne. A las dificultades en torno a la balanza de pagos provocadas por el nuevo direccionamiento del flujo de capitales se les sumaron la caída en los precios de los productos exportables. La reducción de divisas y el deterioro de los términos de intercambio estructuraron un panorama sombrío para la macroeconomía local. La recesión no se hizo esperar y la economía en su conjunto mostró índices de retracción hasta 1932 con la evidente consecuencia del aumento del desempleo que alcanzó su punto más alto justamente ese

Argentina (1870-1940)", en Revista Libertas, Buenos Aires, 1984, No 1. Disponible en: <http://www.eseade. edu.ar/files/Libertas/49_6_Irigoin.pdf>

30. KOROL, Juan Carlos y BELINI, Claudio, Historia económica..., Op. Cit., p. 67 y ss. mismo año. ${ }^{31} \mathrm{La}$ crisis impactó de lleno en los salarios de los trabajadores que observaron un deterioro que se revirtió de modo puntual en 1932 pero sin una tendencia a la mejora general. $^{32}$

El debut público de la CGT empezó a definir su postura frente a la dictadura iniciada en septiembre de 1930. Un tribunal militar había dictado sentencia de condena de muerte para tres choferes del sindicato de la FORA que habían tenido un enfrentamiento armado con la policía. Ante la presión, su manifestación fue un tenue pedido de conmutación de pena $\mathrm{y}$ un voto de confianza al gobierno. ${ }^{33}$ Aunque adjudicada al secretario general Cerutti por el mismo Marotta, la declaración mostraba los esmeros de colaboración de la central y esto la expuso a severas críticas. En consecuencia, la CGT mantuvo negociaciones con el gobierno, en particular con las estructuras del Departamento Nacional del Trabajo (DNT) bajo la gestión de Eduardo Maglione, que le permitieron ejercitar a los sindicalistas las cualidades negociadoras practicadas con especial énfasis durante los gobiernos radicales. En este ejercicio, los socialistas dentro de la central obrera no fueron a la zaga pues valoraron la política laboral de la dictadura durante los primeros meses. Esto no significa bajo ningún aspecto que militantes de base y cuadros medios de ambas corrientes

31. MINISTERIO DEL INTERIOR, DEPARTAMENTO NACIONAL DEL TRABAJO, División de Estadística, Investigaciones sociales, Buenos Aires, 1940, p. 35.

32. Ídem., p. 21 y ss.

33. Citado en MAROTTA, Sebastián, El movimiento sindical argentino. Su génesis y desarrollo. Periodo 1920$1935 \ldots$, Op. Cit., p. 309. 
no sufrieran cotidianamente la represión, tortura, encarcelamiento y deportación que, como complemento, impulsaba el gobierno. La estructura represiva del régimen no se limitó a los clásicos estamentos conocidos pues se formó un nuevo organigrama represivo. ${ }^{34}$

Entre los conflictos puntuales que podemos señalar bajo la dictadura de José F. Uriburu se encuentra el ocurrido en algunas fábricas gráficas durante septiembre de 1930. En las empresas Kraft, Peuser, Fabril Financiera, entre otras, se produjo una huelga por condiciones de trabajo que comenzó con anterioridad al golpe pero luego del 6 de septiembre se puede registrar el modo en que los obreros denunciaban una patronal envalentonada e, incluso, señalaban que: "la Compañía General Fabril Financiera es un arsenal y que en ella se arma a los obreros adventicios y se les incita a provocar desórdenes para perjudicar a los huelguistas". ${ }^{35} \mathrm{Al}$ mes siguiente, el DNT intervino para poner fin al diferendo al reconocer la pertinencia del reclamo obrero sobre la condición de insalubridad del trabajo

34. Uno de los cambios de mayor notoriedad fue la creación de la Sección Especial de Represión del Comunismo a la que se dotó de recursos a la par que se revitalizaron las divisiones Orden Político y Orden Social de la Policía de la Capital Federal, la primera bajo el mando de Leopoldo Lugones hijo, para encuadrar el hostigamiento a los opositores, principalmente los anarquistas y comunistas. A esto se sumaron varias estructuras paraestatales, como la Legión Cívica Argentina. A la orden del día también se colocó la ley de Residencia para la deportación de los inmigrantes. La ley 4.144 o ley Cané recién fue derogada en 1958 bajo la presidencia de Arturo Frondizi. Por ejemplo: Archivo General de la Nación (en adelante AGN), Fondo Uriburu, legajo 11, documento 190, 8/6/1931.

35. La Vanguardia, Buenos Aires, 11/9/1930, p. 5. gráfico en las empresas. ${ }^{36}$ En este extendido conflicto gráfico tuvieron una gran relevancia los comités de huelga de las diversas fábricas.

En 1932, se produjo una modificación del escenario dentro del anarquismo que tuvo repercusión en el movimiento obrero en general y en el gremio gráfico en particular. El 2o Congreso Anarquista Regional de la República Argentina realizado en septiembre de 1932 en Rosario tuvo entre sus resoluciones más relevantes la creación de un Comité Regional de Relaciones Anarquistas (CRRA). ${ }^{37} \mathrm{Su}$ función principal fue la de establecer nexos entre los diversos grupos y propiciar las tareas necesarias para una revitalización de la práctica libertaria. Lejos de limitarse a la coordinación, el CRRA se constituyó como una organización. ${ }^{38} \mathrm{La}$ creación de la Federación Anarco Comunista Argentina (FACA) en 1935 fue consecuencia de la estructura del CRRA aunque no todos los integrantes de éste formaron parte de aquella. Paulatinamente, logró una pequeña representación en tranviarios, gráficos, ferroviarios, industria del vestido y en diversas ramas de la construcción, entre otros. Entre sus militantes más destacados estaban Ángel Geraci, Luis Danussi, Jarislao Prevorsky, Enrique Balbuena, Jacinto Cimazo, Enrique Palazzo, por mencionar algunos de los más

36. La Vanguardia, Buenos Aires, 22/10/1930, p. 5.

37. Este Congreso se realizó de modo legal pues el gobernador demócrataprogresista Luciano Molinas había puesto en vigor la Constitución provincial de 1921 que aseguraba las libertades mínimas para la realización de este tipo de eventos políticos. La idea de 'segundo' reconocería como antecesor al Primer Congreso Regional Anarquista de octubre de 1922.

38. Acción Libertaria, Buenos Aires, 01/09/1933, p. 3. 
importantes ligados al movimiento obrero. En las actas del $2^{\circ}$ Congreso se abordaron los problemas en torno a la cuestión gremial y se señalaba la importancia de destacar la organización de los sitios de producción. Como consecuencia de estos debates se aprobó una resolución que recomendaba "un trabajo constante y metódico dentro de los lugares de trabajo, talleres, fábricas, etc., para organizar luchas inmediatas y para propagar con energía e inteligencia la necesidad de la revolución social para resolver el fenómeno de la bancarrota y de la injusticia capitalistas". ${ }^{39}$ Existía el interés de recuperar las posiciones perdidas frente a otras corrientes y el trabajo de base pretendía ser una respuesta a ello.

No existen certezas sobre el año de fundación de la Alianza Obrera Spartacus (AOS) pero todo indica que fue creada durante 1934. Entre sus principales militantes se destacaba Horacio Badaraco, figura renombrada en el anarquismo argentino. También formaron parte de AOS Antonio Cabrera, Joaquín Basanta y Domingo Varone, quienes cumplieron un rol destacado en el ámbito gremial. A diferencia del CRRA, el trabajo de Spartacus se dirigía prioritariamente a los obreros y a la organización sindical. A partir de su fundación lograron presencia entre los panaderos, gráficos, textiles, lavadores de autos, ladrilleros, transporte, entre otros, pero su principal inserción la obtuvieron en los gremios de la construcción en donde se desempeñaron en simultáneo con la creciente influencia comunista. Pero esto no representó un inconveniente pues pudieron establecer un trabajo mancomunado con los militantes del PC a partir del acuerdo en la conformación

39. La Protesta, Buenos Aires, 05/10/1932, pp. 4-5. de sindicatos por industria. ${ }^{40} \mathrm{El}$ diagnóstico de Spartacus era que el proletariado debía enfrentar una nueva situación y, en consecuencia, se precisaban nuevas respuestas..$^{41}$ Parte del programa sindical de la AOS se materializó en la formulación de lo que denominaron 'Pacto Obrero'. A grandes rasgos, la propuesta giraba en torno a establecer relaciones entre las diferentes corrientes de la izquierda con presencia gremial para construir nexos organizativos que permitieran a cada uno de los grupos mantener su estructura compartiendo información, programas y apoyos con el resto de las agrupaciones. La peculiaridad es que la inserción en la base obrera debía tomar forma en un comité con asiento en la fábrica y en todos los lugares de trabajo como mecanismo de alianza entre los obreros de diversas corrientes políticas. ${ }^{42}$

Para 1935, el importante gremio de los gráficos se encontraba dividido en una serie de sindicatos, aunque dos de ellos eran los más relevantes. Por un lado, la histórica FGB, que contaba con la secretaría general de Luis Ramicone, en la que los socialistas predominaban y, por el otro, estaba la menos importante ULMA que tenía al sindicalista

40. VARONE, Domingo, La memoria obrera. Testimonios (1989), La Rosa Blindada/Cuadernos Marxistas, Buenos Aires, 2004, p. 131.

41. Spartacus. Obrero y Campesino. Comunista Anárquico, Buenos Aires, 01/05/1935, p. 4.

42. CERUSO, Diego, "El trabajo sindical de base del anarquismo argentino: la FACA y la Alianza Obrera Spartacus", en A Contracorriente. Una revista de historia social y literatura de América Latina, Raleigh, 2011, V .VIII, No 3, pp. 233-254. Disponible en: <https://www. ncsu.edu/acontracorriente/spring_11/articles/Ceruso. pdf> 
Marotta como máximo referente. ${ }^{43} \mathrm{~A}$ fines de 1935 los socialistas que integraban la CGT impulsaron un golpe interno al interior de la central obrera y desplazaron de la conducción a los sindicalistas. Esto provocó la división de la Confederación. Los gremios más importantes quedaron enrolados en la CGT conducida por los socialistas (denominada CGT Independencia) a la que al poco tiempo se sumaron los sindicatos dirigidos por los comunistas. Luego de la división de la CGT, la FGB, que hasta allí permanecía autónoma, se incorporó a la ubicada en la calle Independencia mientras que la ULMA recaló en la restante. La decisión de la FGB fortaleció a la central al tiempo que le permitió situarse en una mejor posición para encarar una reorganización del sindicato y obtener mejoras. ${ }^{44}$ Uno de los puntos salientes de esta campaña iniciada era la búsqueda de mecanismos de reconocimiento e institucionalización como el impulso a las comisiones mixtas de patrones y obreros para el cumplimiento de normativas. ${ }^{45}$ En esta línea, en el mes de septiembre de 1936, la FGB presentó un pliego con un pedido de aumento salarial y varias mejoras en las condiciones de trabajo. Declarada la huelga, el sindicato observaba un proceso novedoso: “...en los principales talleres, y especialmente en aquellos donde la asociación no era permitida, fueron creándose pequeños comité de organización que, pacientemente, consolidaron la fuerza sindical de todo el personal en la forma prudente que aconsejaban las circunstancias". ${ }^{46}$

43. Entrevista a Luis Ramicone, Archivo Historia oral/ Instituto Torcuato Di Tella, p. 26.

44. El Obrero Gráfico, Buenos Aires, febrero de 1936, p. 3.

45. Visión, Buenos Aires, 10/01/1936, p. 13.

46. La Vanguardia, Buenos Aires, 14/10/1936, p. 5.
Indudablemente, el gremio gráfico comenzaba a recorrer el sendero de la organización en el sitio de producción, al igual que otros gremios industriales. ${ }^{47}$ Reparemos en el ejemplo de una fábrica en particular.

Luego de varios procesos de fusión y constitución de trusts empresariales en la industria, en 1929 se creó la Compañía General Fabril Financiera, que era un exponente de la extensión de la gran industria en el sector y en donde trabajaban alrededor de 2.500 operarios. ${ }^{48}$ Los obreros de la Fabril Financiera decidieron no acoplarse a la huelga gráfica recién mencionada porque estaban negociando directamente con la patronal y lo hacían a través de una comisión votada por el personal y representativa de las secciones internas. ${ }^{49}$ Para finales de año el esfuerzo organizativo finalmente se cristalizaba y los obreros de la Fabril Financiera obtenían mejoras y para asegurar el cumplimiento el acuerdo establecía: "para cuyo efecto el personal designaría una Comisión Interna integrada por colegas de las distintas secciones". ${ }^{50} \mathrm{Al}$ año siguiente, esto se replicó en otras empresas como por ejemplo en Acevedo y Petrone..$^{51}$ Asimismo, en este avance, la FGB buscó durante 1937 institucionalizar el

47. El proceso de organización de base tuvo máxima expresión en los sindicatos de la construcción, textiles, metalúrgicos, entre otros. CERUSO, Diego, La izquierda en la fábrica. La militancia obrera industrial en el lugar de trabajo, 1916-1943, Colección Archivos, Imago Mundi, Buenos Aires, 2015.

48. BIL, Damián, Descalificados..., Op. Cit., p. 96 y ss.

49. $C G T$, Buenos Aires, 30/10/1936, p. 3.

50. El Obrero Gráfico, Buenos Aires, noviembre y diciembre de 1936, p. 2.

51. El Obrero Gráfico, Buenos Aires, agosto y septiembre de 1937 , p. 3. 
funcionamiento sindical en el lugar de trabajo y en un reglamento, que acordó en el marco de una comisión mixta permanente junto a la Asociación de Industriales del Fotograbado, logró plasmar en el artículo 25 la posibilidad legal que el delegado pudiera cobrar la cuota sindical y repartir impresos gremiales en el taller. ${ }^{52}$ No podemos dejar de mencionar aunque brevemente, que la minoritaria ULMA también esbozó su apoyo a la organización en los sitios de trabajo con la reivindicación de los 'consejos obreros' de taller. ${ }^{53}$

Hacia finales de la década de 1930, el sector gráfico se encontraba en ascenso y los datos en la Capital Federal muestran prácticamente una duplicación de la cantidad de obreros en paralelo a un incremento en torno al 37\% en el número de establecimientos si tomamos como referencia los años 1914 y $1939 .{ }^{54}$ En la misma dirección, la estadística disponible para los censos industriales de 1935 y 1946 evidencian un proceso análogo. Para 1935, se registran 637 establecimientos entre imprentas, litografías y talleres de encuadernación que ocupaban un total de 10.228 obreros; mientras que para 1946, las cifras eran de 1.035 y 20.017, respectivamente. ${ }^{55}$ Esta concentración tuvo su correlato en el aumento de las unidades productivas junto al afianzamiento del proceso de gran industria que lógicamente modificó el proceso de trabajo de modo franco a partir de la

52. MINISTERIO DEL INTERIOR, DEPARTAMENTO NACIONAL DEL TRABAJO,

División de Estadística, Crónica Mensual, XIX, 209/210, julio y agosto de 1937, p. 5079.

53. Mecanotipia, Buenos Aires, 12/10/1936, p. 3, disponible en AGN, Fondo Justo, caja 37, documento 9.

54. BIL, Damián, Descalificados..., Op. Cit., p. 42.

55. En GHIGLIANI, Pablo, "La Federación Gráfica Bonaerense...”, Op. Cit., p. 85. década de 1920, como dijimos. Vale mencionar que el maquinismo y la descalificación fueron factores determinantes para que a finales de los años treinta el sector incorporara el trabajo femenino e infantil que hasta allí no habían sido de gran relevancia. ${ }^{56}$ A partir de 1937, la FGB asistió a una fuerte reorganización que incluyó la incorporación de grupos sindicales que se encontraban por fuera de su estructura. Esto ocurrió en paralelo al desplazamiento de los socialistas de la conducción que quedó en manos de algunos cuadros críticos con el PS, como González Porcel, secretario general entre 1938 y 1939, y del integrante del Partido Socialista Obrero (PSO) René Stordeur, que provenía del PS, quien ocupó ese mismo cargo entre 1940 y $1941 .{ }^{57}$ Este esfuerzo por ampliar y solidificar la estructura sindical se extendió por el territorio argentino con especial énfasis en Rosario, Córdoba, Mendoza, Corrientes, Tucumán, entre las principales provincias. ${ }^{58}$ Asimismo, durante 1939 y 1940, se produjo la unificación de los sindicatos del sector. Bajo la

56. Ídem, pp. 96-136.

57. E1 PSO fue creado en 1937 tras el desarrollo y posterior ruptura de una línea de izquierda al interior del PS. De ella formaron parte importantes cuadros del sindicalismo socialista como Luis Ramicone y Joaquín Coca, ambos del gremio gráfico. HERRERA, Carlos Miguel, "Corrientes de izquierda en el socialismo argentino, 1932-1955”, en Nuevo Topo. Revista de historia y pensamiento crítico, abril-mayo 2006, № 2, pp. 137-141; IÑIGO CARRERA, Nicolás, "Alternativas revolucionarias en los '30: la Alianza Obrera Spartacus y el Partido Socialista Obrero", en BIAGINI, Hugo y ROIG, Arturo (directores) El pensamiento alternativo en la Argentina del siglo XX. T. II. Obrerismo, vanguardia, justicia social (1930-1960), Editorial Biblos, Buenos Aires, 2006, pp. 332-341.

58. Entrevista a René Stordeur, Archivo Historia oral/ Instituto Torcuato Di Tella, pp. 509-513. 
órbita de la FGB se incorporaron la ULMA, la Federación Obrera Gráfica Argentina, pequeño grupo ligado a José Fernando Penelón y su partido Concentración Obrera, y el Sindicato de Obreros Cartoneros y Anexos, ligado al PC a través de la figura de José Cucagna. En este período, la FGB continuó con sus intentos de crear y lograr la proliferación de las comisiones internas aunque con énfasis en las fábricas más importantes. La importancia que le otorgaban al asunto se puede observar en los informes de las comisiones encargadas de fomentar la creación de los organismos de base que asiduamente procuraban mostrar los logros y señalar la dirección buscada por la conducción. $^{59}$

En los últimos meses de 1940, la Federación elevó un petitorio a los industriales que incluía varias reivindicaciones de importancia para el gremio: aumento de salario, un reglamento de trabajo con mejoras en las condiciones, cumplimiento de conquistas previas, efectivización del principio de igual salario por igual tarea y la firma de un convenio colectivo para toda la rama, entre las principales demandas. ${ }^{60}$ En las negociaciones con la Sociedad de Industriales Gráficos de la Argentina, la FGB notificó constantemente a las comisiones internas de taller sobre las resoluciones que se iban adoptando. Incluso, las comisiones internas, sin abandonar el conflicto de su propio gremio, no perdían de vista lo que ocurría en otros sectores como la entidad de base de la empresa Fabril Financiera que enviaba su solidaridad y apoyo en la huelga textil en Ducilo. ${ }^{61}$ Una vez que arribaron a un acuerdo

59. El Obrero Gráfico, Buenos Aires, junio de 1939, pp. 8 y 9.

60. La Vanguardia, Buenos Aires, 20/10/1940, p. 5.

61. La Vanguardia, Buenos Aires, 05/11/1940, p. 5. con la institución patronal, los obreros gráficos realizaron su asamblea general para aprobar el convenio firmado en el que habían obtenido un aumento de salarios, el reconocimiento de las 6 horas y mejoras varias. Pero es importante que reparemos en algunas de las resoluciones de la reunión: " 1 o las comisiones internas o en su defecto el delegado de cada taller deberán preparar, sección por sección, las planillas especiales editadas por la organización... $4^{\circ}$ si el pago se hubiera hecho de acuerdo a la tarifa de salarios deberá la Comisión Interna o el delegado informar a la CGA, presentando las planillas de salarios, especificando las modificaciones producidas en los mismos... $5^{\circ}$ en los casos que se reproduzca la reclamación o conflicto, satisfecho o terminado el mismo, la Comisión Interna o el delegado deberá dar a la CGA el mismo informe." ${ }^{2}$

Evidentemente, el sindicato otorgaba a las comisiones internas un rol de importancia frente al control de las condiciones. Pero los empresarios no aceptaban las mejoras $y$ algunos conflictos se sucedieron en los días subsiguientes y allí las comisiones internas tuvieron una gran presencia: "hoy en el Departamento del Trabajo se reunirán los patrones y comisiones internas de los siguientes talleres: Archelli y Viarengo, Casa América, Casartelli y Fiol, Cowper Coles, Ediciones Católicas, Fumagalli, CADET, Editorial Jackson, Nuñez y Ricci, Parada Obiol y Rem. Estas comisiones han sido citadas para las primeras horas de hoy en el local central de la Federación”. ${ }^{63}$ Estas organizaciones de base de fábricas de menor tamaño mostraban la extensión de la experiencia y funcionaban muchas veces amparadas por aquellas que

62. La Vanguardia, Buenos Aires, 02/12/1940, p. 1.

63. La Vanguardia, Buenos Aires, 12/12/1940, p. 5. 
representaban empresas de mayor envergadura como la comisión interna de Fabril Financiera o la de Rosso que negoció su situación con el empresario por mejoras y encabezó una huelga que duró hasta fines de mes. ${ }^{64}$ Además, para esta época se habían logrado los primeros pasos en la organización en otra de las principales fábricas como Estampa, situada en Bolívar 1616 de la Capital Federal, que contaba una comisión que representaba al personal..$^{65}$ En esta misma fábrica tuvieron cierta injerencia los anarquistas faquistas Luis Danussi y Fernando y Floreal Quesada que abogaron por la organización gremial de la fábrica en la cual el primero fue delegado de sección e impulsó la comisión interna. ${ }^{66}$ Así también se señalaba en la biografía del propio Danussi: "ya entonces existía la Federación Gráfica Bonaerense y gran parte de los personales de los talleres de obra y de los diarios estaban organizados. A poco de constituirse la empresa (octubre de 1938) se designó la Comisión Interna del personal, integrada por delegados de linotipia, tipografía, encuadernación, grabado, montaje, fotografía, retoque, galvanoplastia, mantenimiento y rotativa... Interesa consignar que los delegados cumplían sus funciones como obreros, es decir, no dejaban de trabajar y cuando debían atender asuntos relacionados con el personal o con los de interés general, efectuaban asambleas y reuniones de la Comisión Interna en el local sindical." ${ }^{67}$

64. La Vanguardia, Buenos Aires, 15/12/1940, p. 5; La Hora, Buenos Aires, 10/12/1940, p. 4.

65. Acción Libertaria, Buenos Aires, diciembre de 1940, p. 3 .

66. Entrevista a Luis Danussi, Archivo Historia oral/ Instituto Torcuato Di Tella, 27/11/1971 y 10/12/1971, p. 77.

67. CIMAZO, Jacinto y GRUNFELD, José, Luis Danussi en el movimiento social y obrero argentino (1938-
Ciertamente, aún con matices mediante, esto muestra la existencia y el funcionamiento de las comisiones internas gráficas en las principales empresas, su extensión al resto del gremio, su representatividad respecto de las secciones productivas, su injerencia en las luchas emprendidas y su importancia para la solidificación de la organización que buscaba la FGB. Resulta sugerente que esto, a grandes rasgos, pareció coincidir con un cambio en la dirección del sindicato en favor de cuadros socialistas que cuestionaron las clásicas posiciones y se incorporaron al PSO, al menos momentáneamente. La prueba documental no nos permite extraer conclusiones en este sentido a pesar que queremos destacarlo como posible línea de investigación futura en el caso de los gráficos y las diversas corrientes intervinientes en esta ruptura del PS.

A mediados de 1941, los gráficos organizaron el congreso que constituyó la Federación Argentina de Trabajadores de Imprenta (FATI) como entidad nacional. Allí decidieron no adherir a la CGT lo que provocó la paradoja que su columna vertebral, la Federación Gráfica Bonaerense, estuviera afiliada a una central a la cual la instancia nacional rechazaba. ${ }^{68}$ En la conducción de la FGB, aunque con dificultades, todavía estaban representados los socialistas que habían impulsado una ruptura con el PS y conformado el PSO, que logró colocar en la secretaría general a Riego Ribas, estrecho colaborador de René Stordeur. Además de los circunstanciales integrantes del PSO,

1978), Reconstruir, Buenos Aires, 1981, p. 96; Entrevista a Luis Danussi, Archivo Historia oral/Instituto Torcuato Di Tella, 27/11/1971 y 10/12/1971, p. 77.

68. DI TELLA, Torcuato, Perón y los sindicatos..., Op. Cit., pp. 158 y ss. 
los socialistas, los comunistas, los faquistas y espartaquistas, como dijimos, tenían presencia en el gremio.

En el 20 Congreso ordinario de la FACA, en julio de 1940, se decretó la caducidad de la FORA y se conformó una nueva central denominada Comisión Obrera de Relaciones Sindicales en combinación con los restos de la debilitada USA. Los militantes faquistas integraron hacia 1943 una corriente interna en la FGB que se denominó Agrupación Sindical Gráfica que en su manifiesto-declaración señalaba: "para que estas conquistas no puedan ser burladas por la clase patronal, imponer el reconocimiento de la organización y establecer un estricto contralor, taller por taller, a través de los personales y sus respectivas comisiones internas". ${ }^{69}$ Ya destacamos la labor de Luis Danussi entre los gráficos que junto a los hermanos Quesada abogaron por la organización de la empresa Estampa.

Entre los conflictos gráficos de estos años, se destacó el ocurrido en la empresa Rosso cuando Jacobo Cosin (un antiguo cuadro del PC) renunció a la comisión interna de la fábrica por las reyertas políticas y en la cual el Partido aclaró que lo había expulsado por 'provocador' y desorganizar la base de la fábrica. ${ }^{70} \mathrm{Un}$ tiempo después, hacia fines de 1942, la comisión interna de Rosso, cuyo secretario era Jesús Longeira, reclamaba la reincorporación del José España, integrante de la Comisión Administrativa de la FGB, despedido por la patronal. ${ }^{71} \mathrm{Al}$ igual que los cuadros de la FACA, de la AOS y los socialistas, entre los gráficos,

69. Solidaridad Obrera, Buenos Aires, febrero de 1943, p. 3 .

70. Orientación, Buenos Aires, 09/04/1942, p. 6.

71. La Hora, Buenos Aires, 31/08/1942, p. 4. la minoría comunista expresó su deseo de dotar al sindicato de presencia en las fábricas: "las comisiones internas de taller, lo mismo, adquieren en las circunstancias actuales el valor de un factor decisivo. Dentro del menor plazo posible no debe quedar ningún taller de alguna importancia sin su respectiva comisión interna con vida regular y orgánica". ${ }^{72}$ Aunque los empresarios no cesaban en su organización para frenar este proceso y, apoyados por ejemplo por la Asociación del Trabajo, continuaban con su táctica de implantar escuelas en los sitios de trabajo para instaurar entre los obreros una educación que hiciera eje en la conciliación y los valores nacionales. ${ }^{73}$

\section{Reflexiones finales}

En primer lugar, entendemos que la descripción ofrecida sobre el itinerario de la dinámica sindical se constituye como elemento de valor. El examen del gremio también ofrece una constatación sobre el denso entramado organizativo, sindical y político, que contrasta con una relativa debilidad si atendemos estrictamente a la cuestión numérica de la organización sindical. Pero ello no nos impide señalar que el sindicato tuvo su principal evolución en la faz cualitativa pues el contraste entre la década de 1920 y la de 1930, y muy marcadamente en la segunda mitad de ésta, es sustancial. Al compás de un mundo gremial que ganó fuerza y complejidad, los gráficos solidificaron posiciones en varios ámbitos: reforzaron su poder de negociación, institucionalizaron su funcionamiento,

72. Orientación, Buenos Aires, VI, 255, 04/06/1942, p. 8.

73. Artes Gráficas, Buenos Aires, enero-marzo de 1943, p. 52; Memoria y Balance de la Asociación del Trabajo correspondientes al ejercicio 1942-1943, 1943. 
cimentaron convenios colectivos, expandieron su influencia, entre otros elementos. Pero un punto específico debe ser destacado en ese plano: el interés por la implantación en los sitios laborales. Aunque pudimos registrar el interés desde los tempranos años veinte por obtener presencia en las fábricas, ello se había manifestado casi con exclusividad en la intención de nombrar y/o mantener al delegado gremial. Durante los treinta, pero más marcadamente desde mediados de la década, la organización en el lugar de trabajo definió su fisonomía en torno a la comisión interna de fábrica y sus singularidades: estructuras de base, ligadas al sindicato, elegidas por los obreros, que ejercieron el control y la vigilancia de las condiciones laborales y de los convenios colectivos, con funciones de representación frente a la patronal y con la pretensión concreta de institucionalizar legalmente su existencia y funciones, entre diversas características. Ese triple plano del estudio debe destacarse. El contraste relativo entre alta politicidad y densidad numérica sindical, el robustecimiento de la estructura sindical cuantitativa pero, principalmente, cualitativa con posterioridad a 1930 y el interés por el trabajo de base fabril.

La otra cuestión que queremos destacar es la incidencia de las corrientes políticoideológicas del movimiento obrero del período. Como hemos visto, todas tuvieron un peso destacado en el sector. A la inicial militancia de sindicalistas y socialistas se agregó desde la década de 1920 la de los comunistas y más tarde un remozado anarquismo. Pero en el periodo de tiempo observado el socialismo fue quien ejerció mayor influencia en el gremio, aunque no sin inconvenientes. Primero con la disputa con el sindicalismo, desde mediados de los veinte con el crecimiento del PC desde las fábricas y más adelante con una ruptura, el
PSO, anclada en la crítica del siempre lábil, por inorgánico, vínculo entre el PS y el movimiento obrero. Esto sumado a la más débil pero rejuvenecida labor ácrata de los faquistas y espartaquistas. Justamente por la presencia de todo el arco de las tendencias, es que el gremio gráfico se convierte en un caso interesante para escudriñar las tácticas, estrategias, prácticas, etc., de la izquierda argentina en relación al proletariado fabril. En este sentido, algunos de los aportes de este estudio han sido investigar y valorar los estrechos lazos orgánicos que vincularon al movimiento obrero industrial y a la izquierda en este período permitiendo que ambos coadyuvaran a gestar una profusa experiencia de militancia en los lugares de trabajo.

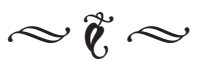

Recibido: 23 - 05 - 2015

Aceptado: 17 - 07 - 2015

Publicado: 30 - 06 - 2016 


\section{Bibliografía}

ARICÓ, José, La bipótesis de Justo. Escritos sobre el socialismo en América Latina, Sudamericana, Buenos Aires, 1999.

BADOZA, María Silvia y TATO, María Inés, "Cuando Buenos Aires se quedó sin diarios: los conflictos de 1919 en la prensa gráfica argentina”, en Sociobistórica Cuadernos del CISH, La Plata, 2006, No 19-20, pp.113-138. Disponible en: <http://www.sociohistorica.fahce.unlp.edu.ar/article/view/SHn19-20a05>

BIL, Damián, Descalificados: proceso de trabajo y clase obrera en la rama gráfica (1890-1940), Ediciones RyR, Buenos Aires, 2007.

CAMARERO, Hernán, "Socialismo y movimiento sindical: una articulación débil. La COA y sus relaciones con el PS durante la década de 1920", en CAMARERO, Hernán y HERRERA, Carlos Miguel (editores) El Partido Socialista en Argentina: sociedad, politica e ideas a través de un siglo, Prometeo, Buenos Aires, 2005, pp. 185-217.

CAMARERO, Hernán, A la conquista de la clase obrera. Los comunistas y el mundo del trabajo en la Argentina, 1920-1935, Siglo Veintiuno Editora Iberoamericana, Buenos Aires, 2007.

CERUSO, Diego, "El trabajo sindical de base del anarquismo argentino: la FACA y la Alianza Obrera Spartacus", en A Contracorriente. Una revista de historia social y literatura de América Latina, Raleigh, 2011, 3, pp. 233-254. Disponible en: <https://www.ncsu.edu/acontracorriente/spring_11/articles/ Ceruso.pdf>

CERUSO, Diego, "El comunismo argentino y sus divisiones en los años veinte. Un análisis de la disputa en el movimiento sindical entre el 'penelonismo' y el Partido Comunista”, en Izquierdas, una mirada histórica desde América Latina, Santiago, 2014, No 18, pp. 37-56. Disponible en: <http://www.izquierdas. cl/ediciones/2014/numero-18-abril-2014>

CERUSO, Diego, La izquierda en la fábrica. La militancia obrera industrial en el lugar de trabajo, 1916-1943, Colección Archivos, Imago Mundi, Buenos Aires, 2015.

CIMAZO, Jacinto y GRUNFELD, José, Luis Danussi en el movimiento social y obrero argentino (19381978), Reconstruir, Buenos Aires, 1981.

DEL CAMPO, Hugo, Sindicalismo y peronismo. Los comienzos de un vinculo perdurable, Siglo Veintiuno Editores, Buenos Aires, 2005.

DI TELLA, Torcuato, Perón y los sindicatos. El inicio de una relación conflictiva, Ariel, Buenos Aires 2003.

DORFMAN, Adolfo, Historia de la industria argentina, Hyspamérica, Buenos Aires, 1986.

FERRER, Nelson, Historia de los gráficos argentinos. Sus luchas, sus instituciones (1857-1957), Dos Orillas, Buenos Aires, 2008. 
GHIGLIANI, Pablo, "La Federación Gráfica Bonaerense y la irrupción del peronismo”, en Sociobistórica Cuadernos del CISH, La Plata, 1998, V. III, No 4, pp. 77-115.

GODIO, Julio, El movimiento obrero argentino (1910-1930). Socialismo, sindicalismo y comunismo, Legasa, Buenos Aires, 1988.

HERRERA, Carlos Miguel, "Corrientes de izquierda en el socialismo argentino, 1932-1955", en Nuevo Topo. Revista de historia y pensamiento crítico, Buenos Aires, 2006, No 2, pp. 137-141.

IÑIGO CARRERA, Nicolás, “Alternativas revolucionarias en los '30: la Alianza Obrera Spartacus y el Partido Socialista Obrero”, en BIAGINI, Hugo y ROIG, Arturo (directores) El pensamiento alternativo en la Argentina del siglo XX. T. II. Obrerismo, vanguardia, justicia social (1930-1960), Editorial Biblos, Buenos Aires, 2006, pp. 332-341.

IRIGOIN, Alfredo, "La evolución industrial en Argentina (1870-1940)”, en Revista Libertas, Buenos Aires, 1984, No 1. Disponible en: <http://www.eseade.edu.ar/files/Libertas/49_6_Irigoin.pdf>

ISCARO, Rubens, Historia del movimiento sindical, T. IV, Fundamentos, Buenos Aires, 1973 (versión anterior: ISCARO, Rubens, Origen y desarrollo del movimiento sindical argentino, Buenos Aires, Anteo, 1958).

KOROL, Juan Carlos y BELINI, Claudio, Historia económica de la Argentina en el siglo XX, Siglo Veintiuno Editores, Buenos Aires, 2012.

MAROTTA, Sebastián, El movimiento sindical argentino. Su génesis y desarrollo. Tomo II. Periodo 1907-1920, Lacio, Buenos Aires, 1961.

MAROTTA, Sebastián, El movimiento sindical argentino. Su génesis y desarrollo. Tomo III. Periodo 19201935, Lacio, Buenos Aires, 1970.

MATSUSHITA, Hiroshi, Movimiento Obrero Argentino 1930-1945: Sus proyecciones en los orígenes del peronismo, Hyspamérica, Buenos Aires, 1986.

ODDONE, Jacinto, Gremialismo proletario argentino, La Vanguardia, Buenos Aires, 1949.

RAPALO, María Ester, Patrones y obreros. La ofensiva de la clase propietaria, 1918-1930, Siglo Veintiuno Editores, Buenos Aires, 2012.

ROCK, David, El radicalismo argentino, 1890-1930, Amorrortu, Buenos Aires, 2010.

TORTTI, María Cristina, Notas sobre la estrategia del Partido Socialista. Reformismo politico y reformismo sindical, Serie Conflictos y Procesos de la Historia Argentina Contemporánea No 34, CEAL, Buenos Aires, 1989.

VARONE, Domingo, La memoria obrera. Testimonios, La Rosa Blindada/Cuadernos Marxistas, Buenos Aires, 2004. 